\title{
Normal-Pressure Hydrocephalus: Is There a Genetic Predisposition?
}

\author{
M.D. Cusimano, D. Rewilak, D.T. Stuss, J.C. Barrera-Martinez, F. Salehi, \\ M. Freedman
}

\begin{abstract}
Background: Normal-pressure hydrocephalus (NPH) is characterized by gait disturbance, cognitive impairment, with or without urinary incontinence, enlarged ventricles with or without cerebral atrophy and normal cerebrospinal fluid pressure. Methods: We report two sisters with NPH who lived together their entire lives and whose natural history might provide insights into genetic and environmental mechanisms underlying this disorder. Both patients were in their early seventies, single, had similar daily habits and hypertension. No other family members had NPH. Results: They both underwent shunt placement and showed improvement documented by history and neuropsychological assessment. Both showed a delayed deterioration due to vasculopathy. Both patients were homozygous for the apolipoprotein E (ApoE) e3 allele on chromosome 19. No environmental factors that might have influenced the development of NPH were identified. Conclusion: Our report of two sisters with NPH may indicate the presence of genetic predisposition and further studies involving genetics and environmental factors are necessary to elucidate their role in the pathogenesis of NPH.
\end{abstract}

RÉSUMÉ: Existe-t-il une prédisposition génétique à l'hydrocéphalie à pression normale? Contexte : L’hydrocéphalie à pression normale (HPN) est caractérisée par un trouble de la marche, une atteinte cognitive avec ou sans incontinence urinaire, des ventricules élargis avec ou sans atrophie cérébrale et une pression normale du liquide céphalo-rachidien. Méthode : Nous rapportons les observations de deux sœurs atteintes de HPN qui avaient vécu ensemble toute leur vie et dont l'histoire naturelle pourrait fournir des indices concernant les mécanismes génétiques et environnementaux sousjacents. Les deux patientes avaient un peu plus de soixante-dix ans, étaient célibataires, avaient des habitudes de vie similaires et étaient toutes deux hypertendues. Aucun autre membre de la famille n'était atteint de HPN. Résultats : Une dérivation a été mise en place chez les deux patientes et elles ont toutes deux eu une amélioration selon l'histoire clinique et l'évaluation neuropsycologique, ainsi qu'un ralentissement de la détérioration due à la vasculopathie. Les deux patientes étaient homozygotes pour l'allèle ApoE3 sur le chromosome 19. Aucun facteur environnemental qui aurait pu influencer la survenue de HPN n'a été identifié. Conclusion : Notre observation de deux sœurs atteintes de HPN pourrait indiquer la présence d'une prédisposition génétique et des études plus poussées de facteurs génétiques et environnementaux devront être faites pour élucider leur rôle dans la pathogenèse de HPN.

Can J Neurol Sci. 2011; 38: 274-281

Normal-pressure hydrocephalus (NPH) is a syndrome characterized by reversible dementia, impairment of gait, urinary incontinence, enlarged ventricles out of proportion to cerebral atrophy and normal cerebrospinal fluid (CSF) pressure ${ }^{1,2}$. Symptomatic hydrocephalus may follow head trauma, subarachnoid hemorrhage, meningitis, intracranial surgery, aqueductal stenosis, or occult brain neoplasia, and its response to surgical shunt is highly predictable. In contrast, the response to shunting in idiopathic NPH is not always favorable ${ }^{3}$. The pathogenesis of NPH is unknown although there is some suggestion that narrowed periventricular arterioles due to hyaline vessel wall degeneration in hypertensive patients might be a risk factor for $\mathrm{NPH}^{4-6}$.

Although NPH is a sporadic disorder, an association between apolipoprotein E (ApoE) e4 has been proposed ${ }^{7}$. Nevertheless, a convincing genetic basis for NPH has not been identified. To our knowledge, there are only a small number of familial NPH reports in the literature and are reported in association with other conditions, namely essential tremor, epilepsy and myotonic dystrophy respectively ${ }^{8-12}$. We report NPH in two sisters; their biological, environmental and pathological similarities might provide insights into the mechanisms underlying this disorder.

\section{Case A}

Case A is a 71-year-old left-handed woman with a one to two year history of gradual onset of progressive writing difficulty, where the wrong word or letter would be produced. Soon after developing difficulty with writing, she noticed a gradual onset of progressive balance problems when she turned quickly or when she put her head back. She had fallen about two or three times. One year prior to assessment, she developed dizzy spells, characterized by a spinning sensation with associated nausea.

\footnotetext{
From the Department of Surgery, Division of Neurosurgery (MDC, FS), St. Michael's Hospital; Department of Psychology (DR), Baycrest Centre; Behavioural Neurology Program (DTS, JCBM, MF), Rotman Research Institute; Department of Medicine (Neurology) (MF), Mount Sinai Hospital, University Health Network; Departments of Surgery, Medicine and Psychology (DTS, JCBM, MF), University of Toronto, Toronto, Ontario, Canada.

Received August 16, 2010. Final Revisions Submitted October 13, 2010. Correspondence to: Michael Cusimano, Division of Neurosurgery, St. Michael's Hospital, 30 Bond Street, Toronto, Ontario, M5B 1W8, Canada.
} 
She also developed memory impairment, which began after the writing and balance deficits. Examples included forgetting directions and misplacing objects. She also had urinary incontinence three to four times a day, which was getting worse. She wet herself because she could not get to the bathroom. She was also incontinent of urine when sneezing or coughing.

Past medical history was positive for hypertension. Medications included Enalapril $10 \mathrm{mg}$ once a day (OD), conjugated estrogen $0.625 \mathrm{mg}$ OD, Ranitidine $150 \mathrm{mg}$ bid, ECASA $325 \mathrm{mg}$ OD, Vitamin E 400 IU OD, and calcium carbonate $500 \mathrm{mg}$ OD. On social history, she completed grade 10; she was single, had no children and lived with a sister; she used to drink one-and-a-half ounces of wine a day but she never smoked. On family history, one sister had difficulty walking. Another sister had breast cancer. One half-brother died in his 60's due to metastatic brain melanoma.

\section{Mental Status Examination ${ }^{13}$}

The Behavioural Neurology Assessment - Long Form was administered $^{13}$ (Table 1). She was appropriate and co-operative. On tests of attention and concentration, she had difficulty on serial 7's subtraction but was able to recite months of the year in reverse order. On tests of memory, she was able to recall $3 / 3$ verbal items immediately but only $2 / 3$ at five minutes. She was oriented to year, month, day, and place. She was one day off on the date. She knew the names of the Prime Minister of Canada, Premier of Ontario and President of the USA. Language examination showed that spontaneous speech, auditory comprehension, naming and repetition were intact. There were spelling errors with self correction on the written description of the Cookie Theft Picture from the Boston Diagnostic Aphasia Exam $^{14}$. On tests of visuospatial function, she lacked threedimensional perspective on drawing a house to command. Drawings of a flower and cube to command were adequate.
Drawing to copy was good. Performance was adequate on the free-drawn clock. On tests of frontal lobe function, she was able to abstract on $3 / 5$ similarities items and $1 / 2$ proverbs. There was no perseveration on drawing multiple loops, ramparts and " $\mathrm{m}$ 's and n's". On word list generation, she produced 16 words beginning with the letter " $F$ " in one minute and 13 animal names. On tests of ideomotor praxis to command, there was no limb, bucco-facial or whole body apraxia.

\section{General Neurological Examination}

Cranial nerves 2-12 were intact. Motor examination showed normal muscle bulk, tone and power. Deep tendon reflexes were grade $2+$ bilaterally. Plantar responses were flexor bilaterally. Sensory system was intact to light touch, pinprick, position and vibration sense. Romberg's sign was absent. On tests of coordination she had normal finger-to-nose, heel-knee-to-shin and rapid alternating movements. Gait was minimally broad based, with decreased arm swing, and minimal weakness in the right leg when walking fast. Tandem gait was impaired. She had a positive snout and a mild glabellar tap reflex.

\section{Neuropsychological Assessment}

Results of this evaluation are summarized in Table 1. She showed decrements on measures of attention, particularly those that placed increased demands on her cognitive processing resources. Mild difficulties in memory were identified, including deficient incidental recall of paired stimuli, a high number of intrusions and perseverations in recalling a word list, inconsistency of recall, susceptibility to information overload, poor encoding of complex visual material, and inefficient retrieval. On a naming task, she showed substantial improvement with cueing, which corroborated her difficulty with retrieval.
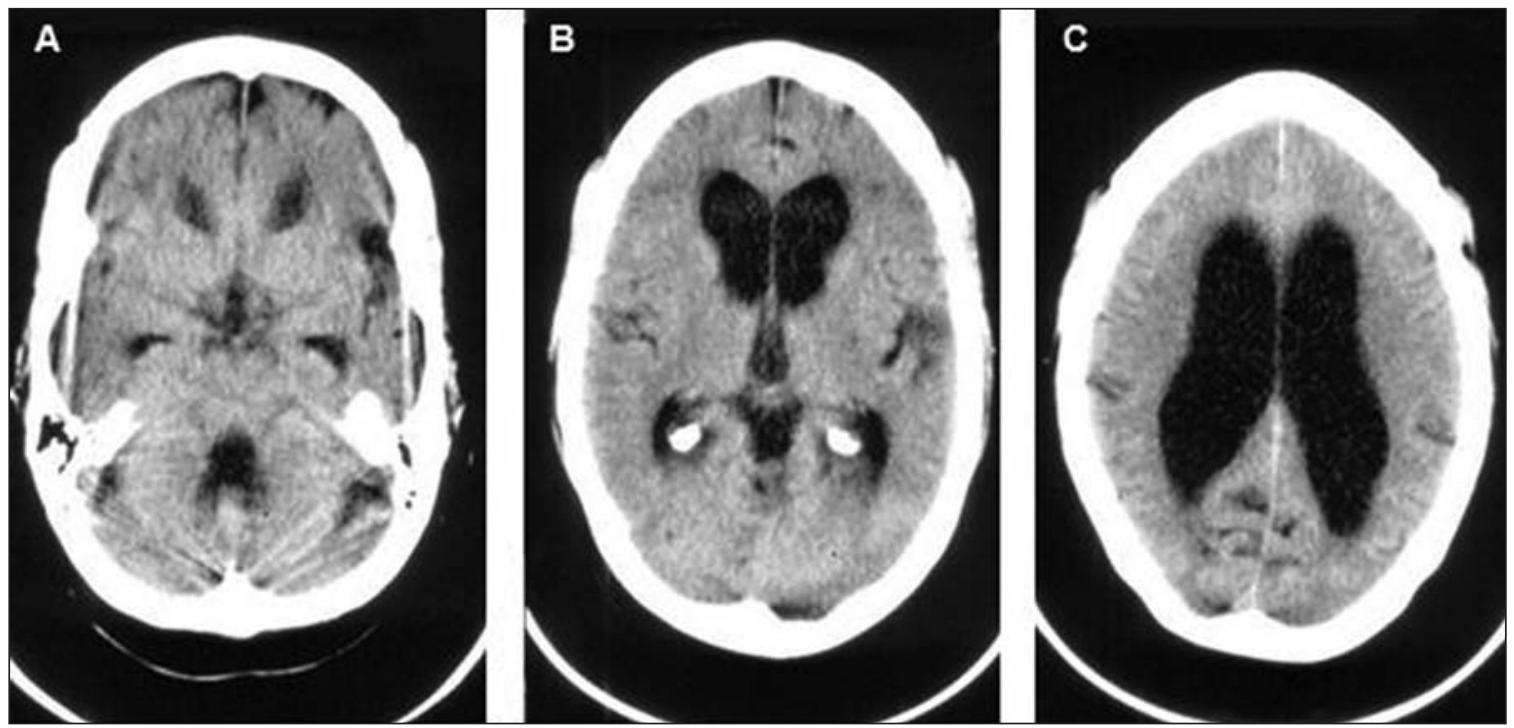

Figure 1: Case A. Pre-operative CT Scan of the head showed enlargement of the ventricles greater than expected for the degree of atrophy present. 
Table 1: Case A

\begin{tabular}{|c|c|c|c|c|c|c|c|}
\hline \multicolumn{8}{|c|}{ Pre- and Post-VP Shunt Clinical Evaluation } \\
\hline Shunt & \multicolumn{2}{|c|}{ Gait } & \multicolumn{2}{|c|}{ Urinary Incontinence } & \multicolumn{3}{|c|}{ Neurologic Examination } \\
\hline Pre- & \multicolumn{2}{|c|}{ Poor balance/falls } & \multicolumn{2}{|c|}{ 3-4 times/day } & \multicolumn{3}{|c|}{ Broad based/weak right leg } \\
\hline Post- & \multicolumn{2}{|c|}{ Normal } & \multicolumn{2}{|c|}{ None } & \multicolumn{3}{|c|}{ Normal gait } \\
\hline \multicolumn{8}{|c|}{ Pre- and Post-VP Shunt Mental Status Examination Scores* } \\
\hline Shunt & Attention & Memory & Language & VSF & Exec & Praxis & Total \\
\hline Pre- & $2 / 4$ & $25 / 28$ & $43 / 50$ & $24 / 24$ & $32 / 40$ & $5 / 5$ & $131 / 151^{\mathrm{a}}$ \\
\hline Post- & $8 / 10$ & $27 / 28$ & $51 / 56$ & $22 / 24$ & $33 / 40$ & $5 / 5$ & $146 / 163^{b}$ \\
\hline
\end{tabular}

* Behavioural Neurology Assessment-Long Form (scoring system based on the version published after the patients were seen ${ }^{8}$

${ }^{\mathrm{a}}$ Prorated total score $=217^{\mathrm{b}}$ Prorated total score $=224$ Pre- and Post-VP Shunt Neuropsychological Assessment

\begin{tabular}{|c|c|c|c|c|c|}
\hline \multirow[t]{2}{*}{ Area of Functioning } & \multirow[t]{2}{*}{ Measure } & \multicolumn{2}{|c|}{ Pre-Shunt } & \multicolumn{2}{|c|}{ Post-Shunt } \\
\hline & & Score & Level & Score & Level \\
\hline Intellectual & WAIS-R (Short Form) & 113 & Hav & & \\
\hline \multicolumn{6}{|l|}{ Ability } \\
\hline \multirow[t]{6}{*}{ Attention } & Digit Span: Forward & 6 & Av & 7 & Av \\
\hline & Backward & 4 & Lav & 4 & Lav \\
\hline & TMT: & $27 "$ & Hav & $28 "$ & Hav \\
\hline & B & $139 ”$ & Lav & $113 ”$ & Av \\
\hline & Digit Symbol & 37 & Av & 46 & Hav \\
\hline & Stroop & 50 & Av & & \\
\hline \multirow{6}{*}{ Memory } & CTT & & & & \\
\hline & CVLT: Trial 5 & 10 & Lav & 12 & $\mathrm{Av}$ \\
\hline & Delayed & 8 & Lav & 9 & Av \\
\hline & Recognition & $91 \%$ & $\mathrm{Av}$ & $91 \%$ & \\
\hline & Rey Figure: Immediate & 5.5 & Bor & & \\
\hline & Delayed & 8 & Lav & & \\
\hline \multirow[t]{2}{*}{ Construction } & Block Design & 25 & Hav & & \\
\hline & Rey Figure & 30 & Av & & \\
\hline \multirow[t]{3}{*}{ Language } & BNT & 49 & $\mathrm{Lav} / \mathrm{Av}$ & & \\
\hline & FAS & 39 & Av & & \\
\hline & Animal Naming & 12 & Lav & & \\
\hline Executive & WCST: Categories & 6 & $\mathrm{Av}$ & & \\
\hline Functioning & Perseverations & 22 & Av & & \\
\hline
\end{tabular}

VSF = Visuospatial function;

Exec $=$ Executive Function;

Praxis = Ideomotor praxis;

WAIS-R = Wechsler Adult

Intelligence Scale-Revised; TMT = Trail Making Test;

Hav $=$ High average ( $>75 \%$ ile.$)$;

CTT = Consonant Trigrams Test;

Av = Average (25-75\%ile.);

CVLT = California Verbal Learning Test

Lav = Low average (9-24\% ile.);

BNT $=$ Boston Naming Test;

Bor $=$ Borderline (2-8\%ile.);

FAS = Verbal Fluency (using letters F,A,S);

Imp = Impaired (<2\%ile.);

WCST $=$ Wisconsin Card Sorting Test;

$+=$ Verbal fluency task exceeded the

normal limit (What does this refer to?)

All scores of the neuropsychological assessment are raw scores with the exception of the WAIS-R score of 113 , which is a standard score (i.e., standard scores have a mean of 100 and standard deviation of 15) and the Stroop score of 50 , which is a T-score (i.e., T-scores have a mean of 50 and standard deviation of 10). In addition, for Digit Span, the score represents the highest number of digits that was repeated forwards and backwards. The same applies to Case B.

\section{Pre-Operative Investigations}

Computed tomogram (CT) scan of the head showed enlargement of the ventricles greater than expected for the degree of atrophy present (Figure 1), which is in agreement with the neuroimaging criteria for diagnosis of $\mathrm{NPH}^{15}$. Magnetic resonance imaging showed that the ventricular system was markedly symmetrically dilated, including the fourth and third ventricles. The sulci of the convexities were not particularly prominent, and there was a rim of abnormal increased signal around the lateral ventricles as well as patchy small foci of deep white matter increased signal on proton density and $\mathrm{T} 2$ weighted sequences. Brain single photon emission tomography (SPECT) showed mild global cerebral perfusion deficit slightly worse on the left side, which although not typical of NPH, however, is suggestive. The CSF flow study showed ventricular reflux with prolonged stasis in the ventricles at 24 hours and there was no activity identified over the convexities.

\section{Response to Shunting}

She had a ventriculoperitoneal (VP) shunt placement, with significant improvement on gait and writing almost immediately 
Table 2: Case B

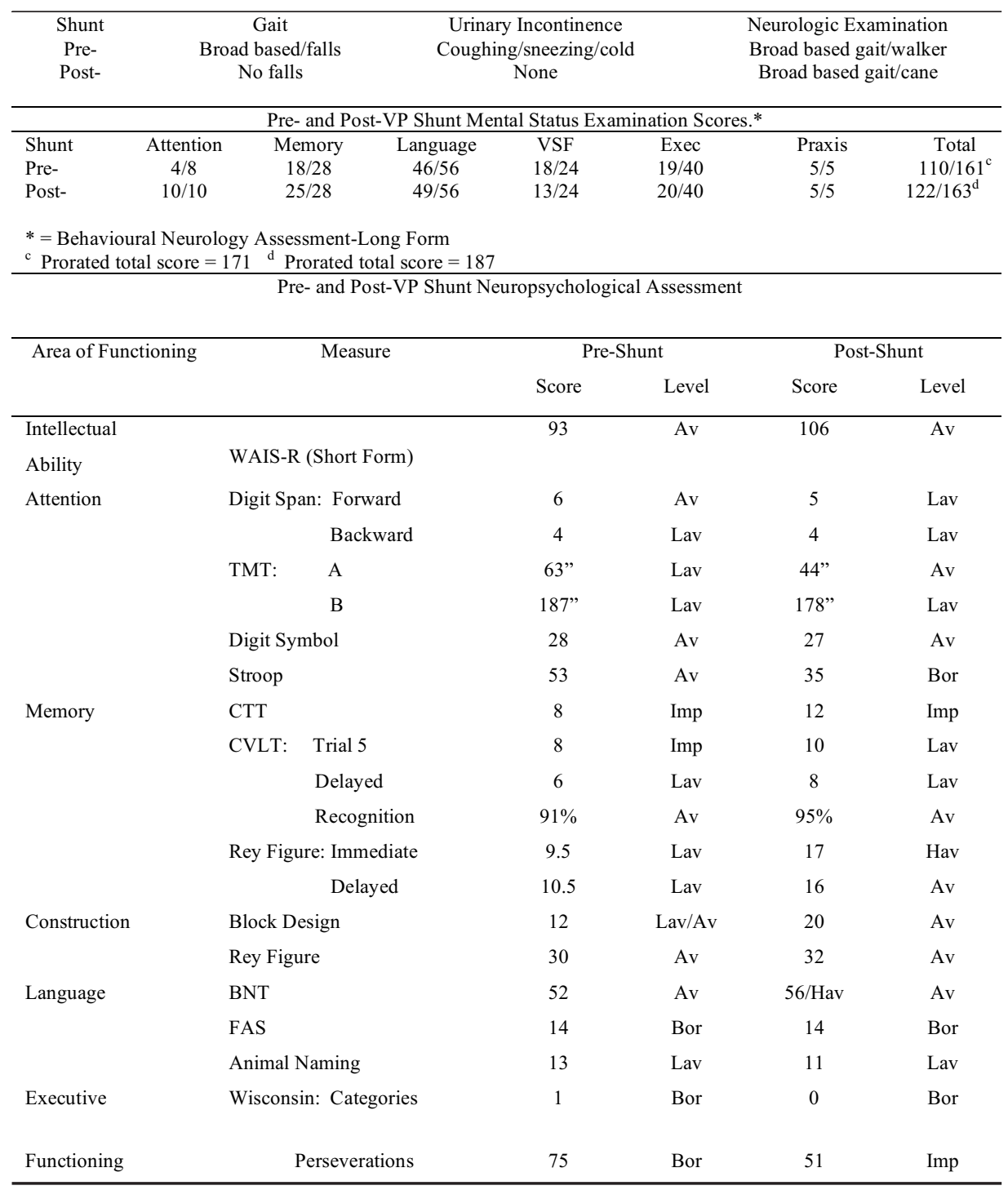

\author{
$\mathrm{VSF}=$ Visuospatial function \\ Exec $=$ Executive Function \\ Praxis $=$ Ideomotor praxis \\ WAIS-R = Wechsler Adult Intelligence \\ Scale-Revised \\ TMT $=$ Trail Making Test \\ Hav $=$ High average $(>75 \%$ ile.$)$ \\ CTT $=$ Consonant Trigrams Test \\ Av $=$ Average $(25-75 \%$ ile. $)$ \\ CVLT $=$ California Verbal Learning Test \\ Lav $=$ Low average $(9-24 \%$ ile .) \\ BNT $=$ Boston Naming Test \\ Bor $=$ Borderline $(2-8 \%$ ile .) \\ FAS = Verbal Fluency (using letters F,A,S) \\ Imp $=$ Impaired $(<2 \%$ ile . \\ WCST $=$ Wisconsin Card Sorting Test
}

The 64-card version of the WCST was used post-shunt. after surgery. This response was maintained for 51 months of follow-up. At that time, she suffered a $3.0 \mathrm{~cm}$ vermian cerebellar hypertensive hemorrhage associated with a blood pressure of 220/100.

\section{Initial Post-Operative Investigations}

The CT scan of the head showed that the ventricles were slightly reduced in size as compared to the previous examination. However, they were still enlarged. Brain SPECT showed no significant interval change in the appearance of cortical perfusion, with mild global deficit slightly worse on the left side. The CSF cytological analysis was negative.

\section{Follow-up Assessment}

Clinical evaluation, mental status examination, and neuropsychological assessment are summarized in Table 1.

\section{CASe B}

Case B is a 73-year-old right-handed woman who developed gradual onset of difficulty walking with stiff legs about four months prior to assessment. She had a progressive course to the point that she was using a walker. She had fallen three to four times. For the six weeks prior to assessment she had noticed that she was not as quick mentally as before. Over the previous year she developed urinary incontinence that occurred only with coughing and sneezing during a cold. 
Past medical history was positive for hypertension. Medications included Lozide $2.5 \mathrm{mg}$ OD, Zantac $150 \mathrm{mg}$ OD, calcium $1500 \mathrm{mg}$ OD, Vitamin D 125 I.U. OD, Vitamin C 500 mg OD, Premarin $0.625 \mathrm{mg}$ OD, and medroxy-progesterone 2.5 mg OD. On social history, she completed grade 12; she was a retired law clerk; she used to drink one-and-a-half ounces of wine a day, she smoked in her teens.

\section{Mental Status Examination ${ }^{13}$ (Table 2)}

She was appropriate and co-operative. On tests of attention and concentration, she had difficulty on serial 7's and serial 3's subtraction but was able to do serial 1's subtraction and recite months of the year in reverse order correctly. On tests of memory, she was able to recall $3 / 3$ verbal items immediately and $0 / 3$ at five minutes. She was oriented to year, month and day but not date. She knew the names of the Premier of Ontario, Prime Minister of Canada and President of the USA. Language examination showed that naming to confrontation was mildly impaired for low frequency items. She benefited from phonemic cues. On language examination, spontaneous speech, auditory comprehension, and repetition were normal. She was able to correctly name 19/20 items. On writing, she produced short phrases rather than a paragraph with sentences on the written description of the Cookie Theft Picture ${ }^{14}$. On tests of visuospatial function she added extra sides when drawing a cube to command. Drawing of a house and flower to command were good. Drawing to copy was good for a house and flower. When asked to copy a cube, she drew a house. Free-drawn clock showed poor spacing of the numbers and omission of the number 1. The number 6 touched the contour. She set the hands at 10 to 11 when asked to set the time 10 after 11 . On frontal lobe tests, she was able to abstract on $1 / 5$ similarities items. She was not able to abstract on $2 / 2$ proverbs. She showed no perseveration on multiple loops and ramparts but had a tendency to perseverate when drawing the "m's and n's". On word list generation she produced six words beginning with the letter " $F$ " in one minute and 11 animal names. On tests of ideomotor praxis to command she was awkward with the left hand for the command to "hammer in a nail". On bucco-facial commands she could not wink with either eye. There was no whole body apraxia.

\section{General Neurological Examination}

Cranial nerves 2-12 were normal. Motor examination showed normal muscle bulk, tone and power. Deep tendon reflexes were grade 2+ bilaterally. Plantar responses were flexor bilaterally. The sensory examination was normal to light touch, pinprick and position sense, but was decreased to vibration sense. On tests of coordination her finger-to-nose and heel-knee-to-shin tests were normal. Rapid alternating movements were normal. Gait was broad based, with short steps (tested without walker). She could not stand with feet together. There was no snout, grasp, glabellar or palmomental reflexes.

\section{Neuropsychological Assessment}

Results of this assessment are provided in Table 2. She showed poor incidental recall of paired stimuli, impaired acquisition and inefficient retrieval of new verbal material, and an impairment in her short-term memory under conditions of interference with evidence of significant proactive interference. In addition, she showed poor organization in copying complex visual material and a reduced ability to generate words according to first letter cues. Her ability to benefit from feedback in order to establish successful problem-solving strategies was also reduced.

\section{Pre-Operative Investigations}

Computed tomogram scan of the head showed ventricular dilatation out of keeping with the degree of cortical atrophy and a small right caudate head infarct (Figure 2). The MRI showed moderate to severe enlargement of the fourth, third and lateral ventricles, prominent signal void within the cerebral aqueduct, third and fourth ventricles on the balanced images, and mildly prominent hemispheric sulci, except at the high convexity where they were hardly identified (Figure 2). There were confluent areas of increased signal in the T2 weighted images within the deep periventricular white matter, several small foci of hypersignal within the more superficial white matter of both frontoparietal regions, and tiny areas of bright signal were identified within the pons. Brain SPECT showed global cortical hypoperfusion, reduced blood flow of the deep gray matter structures, and enlarged ventricles. The CSF flow study showed progressive reflux of radiotracer into the ventricular system at 2 , 5 , and 24 hours.

\section{Response to Shunting}

She underwent shunt placement followed by improvement of gait difficulty quickly after surgery. This improvement had been maintained for 36 months of follow-up and which point she suffered a disabling left middle cerebral artery territory infarction characterized by a progressive language deficit and right hemiparesis, which gradually progressed over two weeks. Cerebral angiography showed a diffuse arteriopathy, and sedimentation rate was normal. Radioisotope study demonstrated a functioning shunt at the time of her infarction.

\section{Post-Operative Investigations}

The CT scan of the head showed mild to moderate hydrocephalus with a right sided ventricular tube that was unchanged in appearance (Figure 3). The remainder of the CT findings were unchanged from the pre-operative scan. Biopsy of the occipital cortex at the time of shunt insertion did not show any evidence of vacuolar or spongiform or any other pathological changes. Immunostaining for beta-amyloid, tau, ubiquitin and congo red were negative.

\section{Follow-up Assessment}

Clinical evaluation, mental status examination and neuropsychological assessment are summarized in Table 2.

\section{GENOTYPE}

Genotyping for the ApoE gene was carried out in both patients using the methodology previously reported ${ }^{16}$. Both case were homozygous for the e3 allele on chromosome 19. 

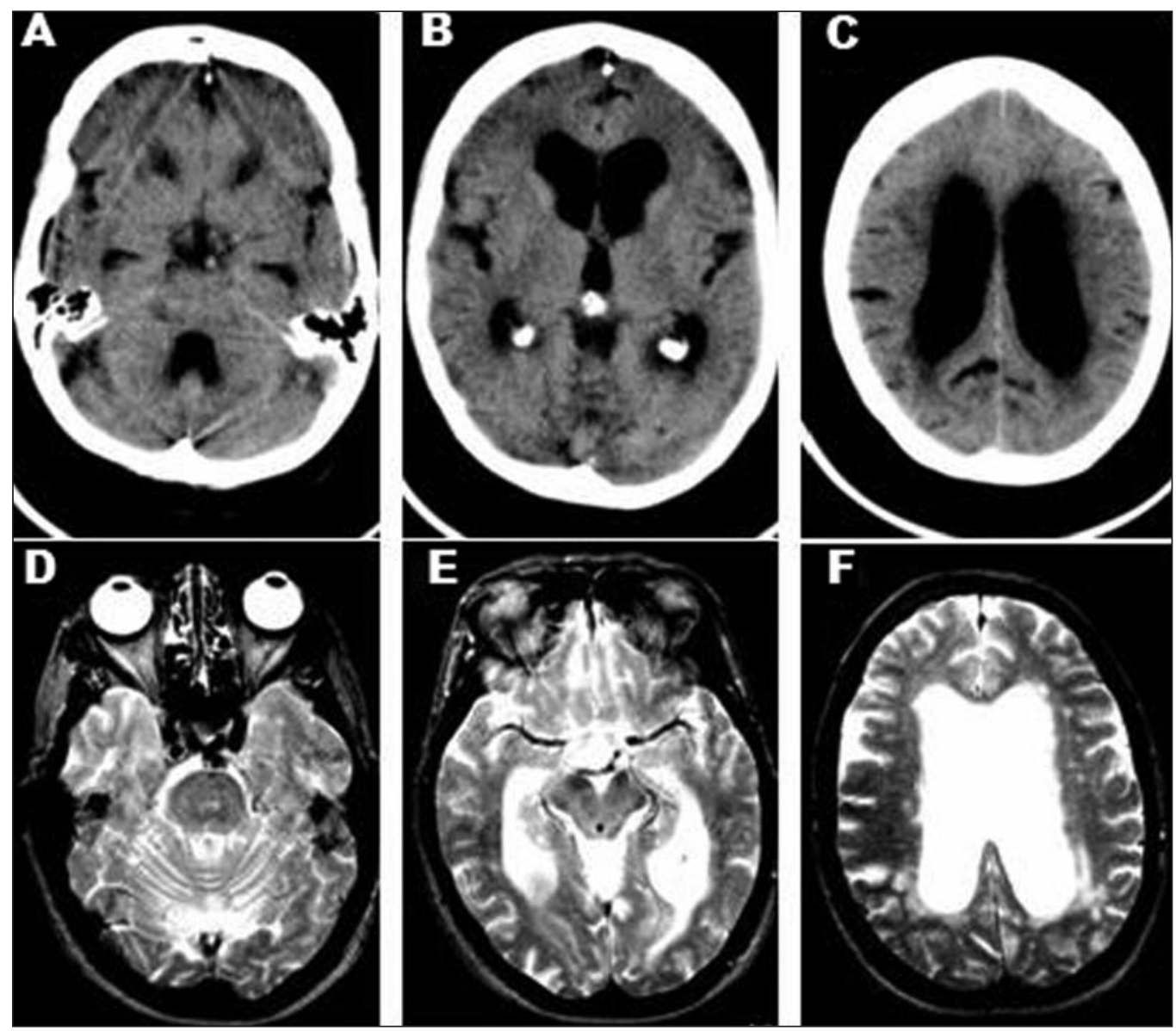

Figure 2: Case B. I) Pre-operative CT Scan of the head showed ventricular dilatation out of keeping with the degree of cortical atrophy. II) Pre-operative MRI showed moderate to severe enlargement of the fourth, third and lateral ventricles, prominent signal void within the cerebral aqueduct, third and fourth ventricles on the balanced images, and mildly prominent hemispheric sulci. There were confluent areas of increased signal in the T2 weighted images within the deep periventricular white matter, several small foci of hypersignal within the more superficial white matter of both frontoparietal regions, and tiny areas of bright signal were identified within the pons.

\section{DISCUSSION}

Our two cases with NPH are unique because they are sisters, who had similar lifestyles and habits. They show the same ApoE genotype: i.e., both are homozygous for the e3 allele. Nevertheless, their clinical profiles differ in certain respects. Case A developed writing impairment that preceded her gait disturbance, and had a longer history of balance problems followed by short-term memory deficits and urinary incontinence, as compared to Case B. In contrast, Case B presented with a rapidly progressive gait disorder, with minor mental slowing and only stress urinary incontinence. On mental status examination, Case B had more deficits in memory, visuospatial function, and executive function (Table 1 and 2). On general neurological examination, Case A had muscle weakness in her right sided extremities and frontal release signs, while Case B had more impaired gait and decreased vibration sense. On neuropsychological assessment, both patients showed the types of difficulties associated with NPH, specifically a reduction in aspects of attention and memory. These difficulties were more pronounced in Case B, who also showed a deficit in flexible problem-solving, an ability that was unaffected in Case A. These differences in presentation suggest that genetic mechanisms that may underlie NPH do not necessarily produce the same phenotype.

Both patients had hypertension. Because narrowed periventricular arterioles due to hyaline vessel wall degeneration ${ }^{4,5,14}$. Moreover, this is supported by the white matter findings on MRI in both patients. The improvement of our cases to shunting provides evidence that white matter changes on MRI do not necessarily imply a poor response to surgical treatment.

Although both patients showed a significant improvement to ventriculoperitoneal shunting, both patients also demonstrated a late deterioration due to vasculopathy several years after the initial presentation. One patient suffered a severe hemorrhage and the other an infarct with demonstrated arteriopathy on 

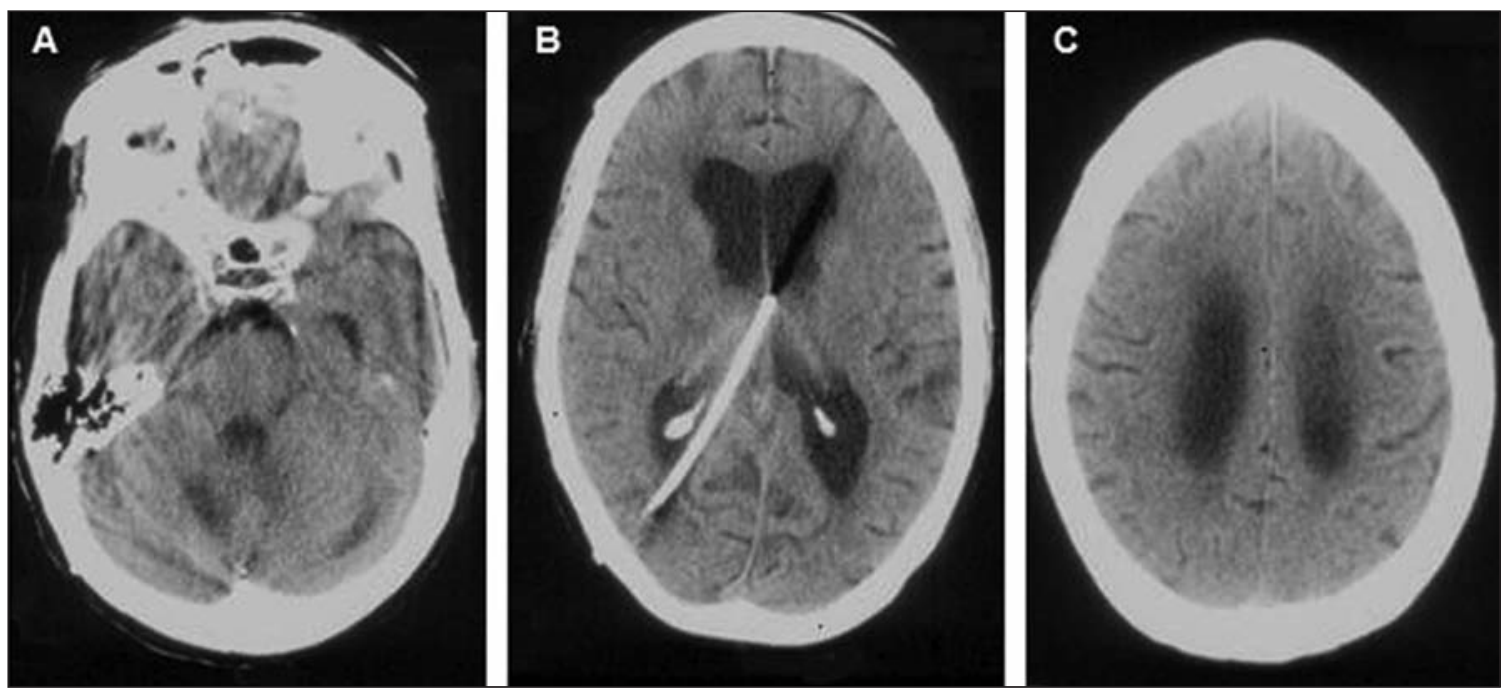

Figure 3: Case B. 36 months post shunt. CT scan of the head showed mild to moderate hydrocephalus with a right-sided ventricular tube that was unchanged in appearance and a left middle cerebral artery territory infarction. Cerebral angiography showed a diffuse arteriopathy.

angiography. These findings raise the issue as to whether the primary disturbance in NPH is in fact, a vascular one, or if in fact the condition is a vascular phenomenon that needs better elucidation.

The ApoE e4 allele on chromosome 19 has been associated with late-onset familial and late-onset sporadic Alzheimer's disease $^{13}$. apolipoprotein $\mathrm{E}$ (ApoE) e4 immunoreactivity is also present in the plaques of Creutzfeldt-Jakob disease, scrapie, Down's syndrome, and other cerebral and systemic amyloidoses ${ }^{17}$. In addition, an association between the ApoE e4 allele on chromosome 19 and sporadic NPH has also been observed, suggesting that e4 allele may be a risk factor in the pathogenesis on $\mathrm{NPH}^{7}$. Nacmias et al found at least one e 4 allele in NPH cases compared to controls ( $23 \%$ versus $6.9 \%, \mathrm{p}=0.017)$. In the same study $^{18}$, the e3 allele was seen in $11 / 13(8 / 13$ homozygous) patients with NPH, but with a significantly lower frequency of the e3 allele compared to controls (73.1\% versus $89.3 \%, \mathrm{p}=0.040)$. However, the number of cases in the Nacmias et al study was relatively small (13 patients with NPH and 108 normal controls). Also, it is not clear whether patients had idiopathic NPH or symptomatic hydrocephalus (4/13 patients were reported to have suffered head trauma), and whether the patients labeled as having NPH actually improved after VP shunting. Our patients, who are sisters, were both homozygous for the ApoE e 3 allele. Whether this represents a chance finding or is a relevant association with NPH is unclear.

Interestingly, ApoD and ApoJ were two of the seven differentially expressed proteins in CSF of idiopathic NPH patients in a recent proteomics analysis ${ }^{19}$. ApoD has also been found to be elevated in the cortex of patients with Alzheimer's disease; no correlation with ApoE levels has been found. ApoE and ApoJ have been implicated in recycling of cholesterol following CNS injury, as well as synaptogenesis and dendritic reorganization ${ }^{20,21}$. Microarray analysis of H-Tx rats, a model of genetic hydrocephalus, showed a series of differentially expressed genes. Such genes as Akt3 and p38 MAPK involved in the amyloidal processing pathway were expressed differentially. Elevated levels of phosphorylated tau protein were detected in the H-Tx rat cerebral tissue, a finding also associated with Alzheimer disease and some reported cases of $\mathrm{NPH}^{22-24}$. In our two cases, tau protein was not detected by immunostaining. Whether tau phosphorylation pathways are implicated in NPH etiology thus remains unclear.

\section{Conclusions}

Although our cases of NPH may represent an extremely rare coincidence, our report of the occurrence of NPH in two sisters, along with a small number of familial cases reported should alert clinicians and researchers about a possible genetic component underlying the development of NPH. A recent report found development of NPH after the age of 65 in a five-generation kindred, preceded by essential tremor in teenage years ${ }^{12}$. It may be proposed that NPH co-segregates with other conditions, as suggested by two other familial reports of NPH. In one report, two elderly siblings presented with NPH and myotonic dystrophy ${ }^{9}$. Yet another report identified epilepsy preceding familial $\mathrm{NPH}^{10}$. These findings highlight the possibility of cosegregation, which may contribute to the ability of clinicians to identify and screen for NPH in at risk family members.

Finally, the role of environment also needs to be considered. These sisters lived together their entire lives. They may have therefore shared environmental as well as genetic risk factors. However, there is currently no data on environmental risk factors for NPH. Further research to address the genetics and possible environmental mechanisms underlying NPH is needed. 


\section{ACKNOWLEDGEMENTS}

Dr. Morris Freedman was supported by the Saul A. Silverman Family Foundation, Toronto, Canada, as part of a Canada International Scientific Exchange Program (CISEPO) project. Personal support for D. Stuss was provided in part by the Reva James Leeds Chair in Neuroscience and Research Leadership.

\section{REFERENCES}

1. Adams RD, Fisher CM, Hakim S, Ojemann RG, Sweet WH. Symptomatic occult hydrocephalus with "normal" cerebrospinalfluid pressure.a treatable syndrome. N Engl J Med. 1965;273: $117-26$.

2. Hakim $\mathrm{S}$, Adams RD. The special clinical problem of symptomatic hydrocephalus with normal cerebrospinal fluid pressure. observations on cerebrospinal fluid hydrodynamics. J Neurol Sci. 1965;2(4):307-27.

3. Vanneste J, Augustijn P, Davies GA, Dirven C, Tan WF. Normalpressure hydrocephalus. Is cisternography still useful in selecting patients for a shunt? Arch Neurol. 1992;49(4):366-70.

4. Earnest MP, Fahn S, Karp JH, Rowland LP. Normal pressure hydrocephalus and hypertensive cerebrovascular disease. Arch Neurol. 1974;31(4):262-6.

5. Hebb AO, Cusimano MD. Idiopathic normal pressure hydrocephalus: a systematic review of diagnosis and outcome. Neurosurgery. 2001;49(5):1166-84; discussion 1184-6.

6. Koto A, Rosenberg G, Zingesser LH, Horoupian D, Katzman R. Syndrome of normal pressure hydrocephalus: possible relation to hypertensive and arteriosclerotic vasculopathy. J Neurol Neurosurg Psychiatry. 1977;40(1):73-9.

7. Casmiro M, D'Alessandro R, Cacciatore FM, Daidone R, Calbucci F, Lugaresi E. Risk factors for the syndrome of ventricular enlargement with gait apraxia (idiopathic normal pressure hydrocephalus): a case-control study. J Neurol Neurosurg Psychiatry. 1989;52(7):847-52.

8. Chalmers RM, Andreae L, Wood NW, Durai Raj RV, Casey AT. Familial hydrocephalus. J Neurol Neurosurg Psychiatry. 1999;67 (3):410-1.

9. Christensen PB. Normal pressure hydrocephalus in myotonic dystrophy. Eur Neurol. 1988;28(5):285-7.

10. Katsuragi S, Teraoka K, Ikegami K, et al. Late onset X-linked hydrocephalus with normal cerebrospinal fluid pressure. Psychiatry Clin Neurosci. 2000;54(4):487-92.

11. Portenoy RK, Berger A, Gross E. Familial occurrence of idiopathic normal-pressure hydrocephalus. Arch Neurol. 1984;41(3):335-7.
12. Zhang J, Williams MA, Rigamonti D. Heritable essential tremoridiopathic normal pressure hydrocephalus (ETINPH). Am J Med Genet A. 2008;146A(4):433-9.

13. Corder EH, Saunders AM, Strittmatter WJ, et al. Gene dose of apolipoprotein $\mathrm{E}$ type 4 allele and the risk of alzheimer's disease in late onset families. Science. 1993;261(5123):921-3.

14. Goodglass H, Kaplan E. Boston diagnostic aphasia examination (BDAE). Philadelphia: Lea and Febiger; 1983.

15. Gallassi R, Morreale A, Montagna P, Sacquegna T, Di Sarro R, Lugaresi E. Binswanger's disease and normal-pressure hydrocephalus. clinical and neuropsychological comparison. Arch Neurol. 1991 Nov;48(11):1156-9.

16. Darvesh S, Leach L, Black SE, Kaplan E, Freedman M. The behavioural neurology assessment. Can J Neurol Sci. 2005;32 (2): $167-77$.

17. Saunders AM, Strittmatter WJ, Schmechel D, et al. Association of apolipoprotein E allele epsilon 4 with late-onset familial and sporadic alzheimer's disease. Neurology. 1993;43(8):1467-72.

18. Nacmias B, Tedde A, Guarnieri BM, et al. Analysis of apolipoprotein E, alpha1-antichymotrypsin and presenilin-1 genes polymorphisms in dementia caused by normal pressure hydrocephalus in man. Neurosci Lett. 1997;229(3):177-80.

19. Li X, Miyajima M, Mineki R, Taka H, Murayama K, Arai H. Analysis of potential diagnostic biomarkers in cerebrospinal fluid of idiopathic normal pressure hydrocephalus by proteomics. Acta Neurochir (Wien). 2006;148(8):859-64; discussion 864

20. Messmer-Joudrier S, Sagot Y, Mattenberger L, James RW, Kato AC. Injury-induced synthesis and release of apolipoprotein $\mathrm{E}$ and clusterin from rat neural cells. Eur J Neurosci. 1996;8(12): 2652-61.

21. Poirier J. Apolipoprotein E in animal models of CNS injury and in Alzheimer's disease. Trends Neurosci. 1994;17(12):525-30.

22. Arai H, Higuchi S, Sasaki H. Apolipoprotein E genotyping and cerebrospinal fluid tau protein: Implications for the clinical diagnosis of Alzheimer's disease. Gerontology. 1997;43 Suppl $1: 2-10$.

23. Grundke-Iqbal I, Iqbal K, Quinlan M, Tung YC, Zaidi MS, Wisniewski HM. Microtubule-associated protein tau. A component of Alzheimer paired helical filaments. J Biol Chem. 1986;261(13):6084-9.

24. Grundke-Iqbal I, Iqbal K, Tung YC, Wang GP, Wisniewski HM. Alzheimer paired helical filaments: cross-reacting polypeptide/s normally present in brain. Acta Neuropathol. 1985;66(1):52-61. 